\title{
İnsani Yardım, Özgür ve Açık Kaynak Kodlu Yazılım Projeleri (İÖAKK)
}

\author{
H. Selcuk Nogay ${ }^{\mathrm{a} 1, *}$, Tahir Cetin Akınci ${ }^{\mathrm{b} 1}$, Serhat Şeker ${ }^{\mathrm{b} 2}$ \\ a Kayseri Üniversitesi, Mustafa Çıkrıkçıŏ̆lu MYO, Elektrik ve Enerji Bölümü, Kayseri, Türkiye. \\ b İstanbul Teknik Üniversitesi, Elektrik Mühendisliği Bölümü, İstanbul, Türkiye.
}

İstanbul Sabahattin Zaim Üniversitesi Fen Bilimleri Enstitüsü Dergisi (2020) 2 (3): $72-75$

https://doi.org/10.47769/izufbed.860010

(iD) ORCID ${ }^{1} 0000-0001-9105-508 \mathrm{X} ;{ }^{2} 0000-0002-4657-6617 ;{ }^{3} 0000-0001-5816-2211$

\begin{tabular}{l}
\hline YAYIN BİLGİSİ \\
\hline Yayın geçmişi: \\
Gönderilen tarih: 13 Ocak 2021 \\
Kabul tarihi: 17 Mart 2021 \\
\hline Anahtar kelimeler: \\
İnsani Yardım \\
Özgür ve Açık Kaynak Kodlu \\
Yazılım \\
Bilg İşlem \\
Bilgisayar Mühendisliği \\
Proje \\
\hline
\end{tabular}

\begin{tabular}{|c|}
\hline ÖZET \\
\hline $\begin{array}{l}\text { İnsani yardım amacıyla açık kaynak kodlu yazılım platformları projelendirildiğinde biç ok } \\
\text { topluma yararlı yazılım ve programlar ortaya çıkmaktadır. Engelliler için erişilebilirlik, afet } \\
\text { durumlarında kriz yönetimi, sağlıkla ilgili vb konularda açık kaynak kodlu yazılıp platformları } \\
\text { insani yardım amacıyla geliştirilebilir. Bu geliştirme sürecinde de üniversite öğrencilerinden } \\
\text { yararlanılabilir. Üniversitelerin ilgili bölümünde okuyanlar için IÖAKK projeleri hem yazılım } \\
\text { tecrübelerini ve mesleki bilgilerini geliştirme firsatı hem de sosyalleşme ve toplumun çıarları } \\
\text { için iş yapma fırsatı sağlanmış olur. Bu çalışmada insani yardım amaçlı kullanılan AKK yazılım } \\
\text { projelerinin dünyada nasıl şekillendiği ve gerek eğitim öğretim açısından ve gerekse toplum } \\
\text { hizmeti açısından nasıl sonuçlar doğurduğu araştırılmıştır. ÏÖAKK projelerine üniversite } \\
\text { öğrencilerinde katılması ile bazı ülkelerde destek sağlandığı ve çok iyi sonuçlar alındığ1 } \\
\text { görülmüştür. Ülkemizde de benzeri girişim potansiyelinin olduğu göz önünde bulundurularak } \\
\text { ÏÖAKK projelerinin mutlaka üniversite öğrencileri için firsat haline getirilerek ülkemizde de } \\
\text { arttırılması gerektiği sonucuna varılmıştır. }\end{array}$ \\
\hline
\end{tabular}

\section{Humanitarian, Free and Open Source Software Projects (HOSSP)}

\begin{tabular}{l}
\hline ARTICLE INFO \\
\hline Article history: \\
Received: 13 January 2021 \\
Accepted: 17 March 2021 \\
\hline Key words: \\
Humanitarian \\
Free and Open Source Software \\
Computing \\
Computer Engineering \\
Project
\end{tabular}

\begin{abstract}
When open source software platforms are designed for humanitarian aid, many socially beneficial software and programs emerge. Open source software platforms can be developed for humanitarian aid in accessibility for the disabled, crisis management in disaster situations, healthrelated issues, etc. The contribution of especially university students to this development process can be great. For those studying in the relevant department of university students, humanitarian free and open source software (HFOSS) projects provide the opportunity to develop their software experience and professional knowledge, as well as socialize and do business for the benefit of society. In this study, how HFOSS projects are shaped in the world and what kind of results they have in terms of education and community service are investigated. With the participation of university students in HFOSS projects, it was observed that support was provided in some countries and very good results were obtained. Considering that there is a similar initiative potential in our country, it is considered that HFOSS projects should be increased in our country by making them an opportunity for university students.
\end{abstract}

\section{Giriş}

Açık kaynak yazılım platformları 2006 yılından itibaren insani yardım amaçlı yazılımların doğması için önemli bir araç olarak kullanılmaktadır. İnsani yardım amaçlı olarak açık kaynak yazılım platformlarının kullanılması sonucu ortaya çıkan insani yardım projeleri ile birçok araştırmacı, üniversitelerin lisans eğitimi öğrencilerinin insani yardım amacıyla önemli bir iş gücü olarak görülebileceğini ortaya attılar. Ancak üniversitelerde bilgi işlem eğitmenleri açısından düşünüldüğünde de insani yardım özgür ve açık kaynak kodlu (İÖAKK) yazılım projelerinin öğrencinin lisans eğitimine büyük katkılar sağladığı ortaya çıkmıştır. İnsani Yardım Özgür Açık Kaynak Yazılımı (İÖAKK), genellikle insan koşullarını iyileştirmeyi amaçlayan kar amacı gütmeyen kuruluşlardan yararlanan hayırsever hedeflere hizmet eder. Bu özgür platform sayesinde günümüzde dünyada bazı ülkelerde bir çok İÖAKK projesi hayata geçmiş ve birçok bilgi işlem 
veya yazılım lisans programı ögrencisi bu etkinlikler yolu ile kendisini ve yazılım kabiliyetlerini geliştirme firsatı bulmuştur.

Bu çalışmada, günümüze kadar gelen süreçte dünyada gerçekleştirilen İÖAKK yazılım projeleri araştırılmış, bu projelerin lisans eğitimine ve insanlığa katkısı ele alınmıştır.

\section{2. İlgili çalışmalar ve İÖAKK yazılım projeleri}

İÖAKK yazılım projeleri ile dünyanın farklı ülkelerinde tamamlanmış projeler vardır. Tablo 1 de bu projelerden bazıları gösterilmektedir. Sağlık yönetimini iyileştirmekten körler için erişilebilir yazılım çözümleri oluşturmaya kadar çeşitli özgecil amaçlara hizmet etmeye çalışan ürünler bu projelerin başarıya ulaşması sonucunda ortaya çıkmıştır (Hislop vd., 2009).

Afet olayları sırasında insani kurtarma organizasyonlarının karşılaştı̆gı iki temel zorluk vardır (a) hasar ve gerekli eylemlerle ilgili yer seviyesinde istihbarat toplamak; (b) koordinasyona yardımcı olmak ve insanların ihtiyaçlarını ve konumlarını bildirmelerine yardımcı olmak için iletişimlerin yeniden kurulması. Temel altyap1 kayb1 veya kapasite eksikliği nedeniyle bir felaket sırasında cep telefonları çalışmayı durdurarak savunmasız veya yardıma ihtiyacı olan kişiler için iletişim kaybına neden olabilir. İlk müdahale ekipleri ayrıca bilgileri İletişim kontrolüne geri gönderemez. Bu nedenle iletişimin yeniden kurulması kritik öneme sahiptir ve geçici drone ağı ile etkin nokta oluşturma yoluyla sağlanabilir (O'Keeffe vd., 2018).

Bir araştırmada İÖAKK projelerinin en fazla desteklediği alanların sağlık hizmeti, erişilebilirlik ve kamu yönetimi olduğu ortaya çıkmıştır. Sağlık hizmetleri, çeşitli büyüklükteki kurumlarda sağlık kalitesini iyileştirmeye ve sağlık hizmeti sunumunu yönetmeye yönelik her türlü sistemi kapsar. Erişilebilirlik, amacı engelli kişilerin yaşam kalitesini iyileştirmek olan tüm sistemleri gruplandırır (ör. Görme, işitme bozuklukları). Sivil toplum kuruluşları (STK) yönetim alanı, STK'lar içinde kaynakların yönetimine yönelik tüm sistemleri kapsamaktadır Mikrofinans, geleneksel olarak bankacılık ve ilgili hizmetlere erişemeyen, tüketiciler ve serbest çalışanlar da dahil, düşük gelirli müşterilere veya kredi dayanışma gruplarına finansal hizmetlerin sunulmasıdır. Gıda bankası yada gıda bankacılığı, bağışlanmış gıda, giysi, temizlik ve hijyen ürünlerini toplayan, ayrıştıran, depolayan ve ihtiyaç sahiplerine dağıtan bir sivil toplum örgütlenmesidir. Tablo 2' de İÖAKK projelerinin desteklediği sahalar gösterilmektedir (Parra et al 2016).

Başka bir çalışmada, derin evrişimsel sinir ağları uydu görüntüleri ile eğitilerek insani yardım ve ekonomik kalkınma için binaları, yolları vb. etiketleme amacıyla uygulanmış ve \% 86 doğruluk oranı elde etmiştir (Chen et al 2019). IEEE, 2004 yılından beri insani yardım amaçlı açık kaynaklı yenilikleri insanlarla tanıştırmak için organizasyonlar düzenlemektedir. 2009 yılında insani teknoloji yarışması düzenledi. IEEE'nin sponsor olduğu İÖAKK insani faaliyetleri kapsamında IEEE gönüllüleri tarafından geliştirilen fikri mülkiyet haklarını korumaya yönelik açık kaynak lisansları sunmaktadır (Herrera ve Prowse 2015).
Tablo 1. Tamamlanmış ve uygulanmış İÖAKS proje örnekleri

\begin{tabular}{|c|c|}
\hline Proje adı & Açıklaması \\
\hline Sahana & $\begin{array}{l}\text { Acil durum müdahale ekiplerinin afetleri } \\
\text { daha verimli ve etkili bir şekilde } \\
\text { yatıştırmalarına, hazırlanmalarına, } \\
\text { müdahale etmelerine ve afetzedelerin } \\
\text { kurtarılmalarına yardımcı olan bir afet } \\
\text { müdahale yönetim sistemidir (Ellis vd., } \\
\text { 2007). }\end{array}$ \\
\hline OpenMRS & $\begin{array}{l}\text { Başlangıçta Afrika'daki HIV hastalarının } \\
\text { tedavisini iyileştirmek için tasarlanmış } \\
\text { bir tıbbi kayıt sistemi olan ve şu anda } \\
\text { gelişmekte olan ülkelerde sağlık } \\
\text { hizmetlerinin sunulmasını destekleyen } \\
\text { kayıt sistemidir (Kimei ve Khamisi } \\
\text { 2017). }\end{array}$ \\
\hline Ushahidi & $\begin{array}{l}\text { Kriz ve şiddete dayalı toplumsal olayları } \\
\text { haritalamak için kullanılan, Kenya'nın } \\
\text { tartışmalı } 2007 \text { başkanlık seçimlerinin } \\
\text { ardından şiddet raporlarını izlemek için } \\
\text { oluşturulmuş, kitle kaynaklı bir } \\
\text { haritalama aracıdır (Shen 2015). }\end{array}$ \\
\hline GNOME & $\begin{array}{l}\text { Engelli kullanıcılar için Linux'a erişimi } \\
\text { destekleyen Orca ekran okuyucu gibi bir } \\
\text { erişilebilirlik aracıdır (Walters et al } \\
\text { 2013). }\end{array}$ \\
\hline KoboCollect & $\begin{array}{l}\text { İnsani yardım ve araştırma kuruluşlarını } \\
\text { desteklemek için tasarlanmış açık } \\
\text { kaynaklı bir veri toplama yazılımı } \\
\text { platformudur (Peter vd., 2018). }\end{array}$ \\
\hline SoftHum & $\begin{array}{l}\text { İnsani yardım amaçlı açı kaynak } \\
\text { projelerinde lisans öğrencilerinin } \\
\text { katılımını desteklemek için açık kaynak } \\
\text { ders materyalleri geliştirme projesidir } \\
\text { (Ellis vd., 2008). }\end{array}$ \\
\hline OpenGarden & $\begin{array}{l}\text { Dizüstü bilgisayarlar, tabletler ve } \\
\text { telefonlar arasında internet bağlantılarını } \\
\text { WiFi bağlantı noktalarına benzer şekilde } \\
\text { paylaşan iletişim aracıdır (O'Keeffe vd., } \\
\text { 2018). }\end{array}$ \\
\hline Serval Mesh & $\begin{array}{l}\text { Akıllı telefonların iletişim kurmasını } \\
\text { sağlayan iletişim aracıdır (O'Keeffe vd., } \\
\text { 2018). }\end{array}$ \\
\hline SDR & $\begin{array}{l}\text { Mobil İletişim İçin Global Sistem (GSM) } \\
\text { aracılığıyla kullanıcı nirengi için temel } \\
\text { alıcı-verici istasyon yazılımına sahip } \\
\text { Yazılım Tanımlı Radyo (SDR) (O'Keeffe } \\
\text { vd., 2018). }\end{array}$ \\
\hline
\end{tabular}

AKK yazılım platformları yardımıyla yapılabilecek ancak KKK yazılım platformları ile oluşturulmuş olan insanlığa hizmet edebilecek potansiyelde çalışmalar vardır. $\mathrm{Bu}$ çalışmalardan birisinde, görme engelli öğrencilerin teknik ve mesleki bir lisans bölümüne ait otomasyon laboratuvarında yapılan deneyleri ve elemanları tanıması için algoritma geliştirilmiştir (Nogay ve Akinci 2011). Benzer şekilde AKK platformlarında rahatlıkla gerçekleştirilebilir olan kanser hastalık tiplerinin sınıflandırmaları (Nogay vd., 2018; Nogay 2018), teşhis ve seviye (Nogay vd., 2018) ve yer (Nogay ve 
Akinci 2018) tespitleri (Nogay 2017), hayatta kalma süresi tahminleri (Nogay 2020), otizm erken teşhisi (Nogay ve Adeli 2020) çalışmaları KKK platformlarında yapılmış olan örnek çalışmalar olarak gösterilebilir.

Tablo 2. İÖAKK için Uygulama Etki Alanları [9]

\begin{tabular}{|l|l|l|l|}
\hline Alan & Projeler & Alan & Projeler \\
\hline $\begin{array}{l}\text { Sağlık } \\
\text { hizmeti }\end{array}$ & $\% 30$ & Eğitim & $\% 8$ \\
\hline Erişilebilirlik & $\% 21$ & Kütüphaneler & $\% 4$ \\
\hline STK & $\% 12$ & Mikrofinans & $\% 4$ \\
\hline $\begin{array}{l}\text { Afet } \\
\text { yönetimi }\end{array}$ & $\% 9$ & Çevre & $\% 3$ \\
\hline $\begin{array}{l}\text { Gıda } \\
\text { bankacılığ } 1\end{array}$ & $\% 3$ & İnsan hakları & $\% 3$ \\
\hline Mahremiyet & $\% 3$ & & \\
\hline
\end{tabular}

\section{3. İÖAKK projelerinin eğitme katkısı}

Tayvan da 2003 yılında AKK yazılımları üniversitelerde tanıtılmaya başlandı ve üniversite öğrencilerinin yararına AKK yazılımları kullanılmaya başlandı (Hsu 2012). Amerika Birleşik Devletleri'nde (ABD) 2006'da başlayan İÖAKK projelerinin ilk amacı hem yerel hem de küresel olarak insanlığa fayda sağlayan ücretsiz ve açık kaynaklı yazılımlar oluşturarak, bilgisayar bilimlerindeki lisans öğrencilerini bu projelere dahil etmekti. İÖAKK projeleri ABD de, Ulusal Bilim Vakfi, Accenture, Google ve Mozilla dahil olmak üzere çeşitli ortaklardan maddi destek alarak günümüze kadar gelmiştir (Tucker ve Morelli 2011). Bazı çalışmalarda yazılım mühendisliği öğrencilerinin İÖAKK yazılım projeleri vasıtasıyla eğitilmeleri desteklenmektedir. İÖAKK yazılım projeleri, ücretsiz çalışan gönüllüler sayesinde (Kevin 2016) bilgisayar eğitimcilerinin öğrencilerine küresel insani zorlukların üstesinden gelmeleri için ilham verirken aynı zamanda yazılım mühendisliğini öğrenmeleri için bir firsat sağlamaktadır. İÖAKK yazılım projeleri, öğrencilere gerçek yazılım sistemlerine katkıda bulunma ve çeşitli topluluklara katılma firsatları sunarak, öğrencilerin hem içerik hem de süreç becerilerinde ustalaşmalarına yardımcı olmaktadır (Kussmaul 2016).

İÖAKK projeleri, ayrıca, öğrencilere bir sosyal sorumluluk anlayışı da kazandırabilir. Çoğu bilgisayar eğitimi programı, bir kurs aracılığıyla bilgi işlemin sosyal yönlerini veya bir kurs içindeki konuları içerir. Ancak, bilgi işlem bilgisinin geniş ve sürekli büyüyen yapısı göz önüne alındığında, genellikle güvenlik konularına odaklanılır (güvenlik tehditleri, yazılımın zarar verme potansiyeli vb.). Başka bir deyişle öğrencilere yazılımın iyilik yapma potansiyelini öğretmek için geriye çok az bir zaman kalır. Ders sayısı fazla olan yoğun bir müfredatta, İÖAKK projeleri, sosyal sorumluluğu tanıtmanın hem ayrıntılı vaka çalışmaları hem de uygulamalarla deneyim kazanma yoluyla öğrenci perspektiflerini genişletmenin etkili bir yolu olabilir. Öğrenciler, topluma katkıda bulunmanın değerini daha iyi anlayabilir ve bilgi işlem becerilerini yardıma ihtiyacı olanlar için kullanabilmenin önemini anlayabilirler.

2006'dan beri İÖAKK etkinliklerinin öğrenci öğrenimi üzerindeki etkisi çeşitli araştırmacılar tarafından araştırılmaktadır. Yedi kurumda yapılan çok sayıda çalışma ve 200'den fazla öğrencinin katıldığı bir araştırmada aşağıdaki gözlemler yapılmıştır (Hislop ve Ellis 2017).

- Öğrenciler, bir İÖAKK projesine katılarak önemli bir bilgi işlem bilgisi kazandıklarını anlarlar.

- Öğrenciler, bir İÖAKK projesi geliştirmek için yazılım becerilerinde bir artış algılar.

- Genel olarak, bir İÖAKK projesine katılarak, öğrenciler dağıtık bir ortamda yazılım geliştirme konusunda deneyim kazandıklarını ve iletişim, problem çözme ve dağıtılmış ekip çalışması gibi profesyonel beceriler kazandıklarını bildirirler (Hislop ve Ellis 2017).

\section{Sonuç ve öneriler}

Açık kaynak kodlu yazılım platformları yardımıyla ülkemizde de insani yardım amaçlı yazılımlar üretilebilir ve bu konu ile ilgili projeler başlatılabilir Diğer ülkelerde olduğu gibi İÖAKK yazılım projeleri bir etkinlik olarak görülerek, üniversitelerde ilgili bölümlerin eğitimleri yararına kullanılabilir. Böylelikle hem öğrencilerin yazılım tecrübeleri artmış olur hem de insanlığa hizmet eden projeler üretilir. AKK yazılım platformları sadece yazılım veya bilgi işlem öğrencileri ve araştırmacıları için değil aynı zamanda yazılım merakı olan bütün gençler için ücretsiz ve özgür erişilebilirdir. $\mathrm{Bu}$ sebepledir ki, ülkemizin genç nüfus oranı da dikkate alındığında İÖAKK projelerinin geliştirilmesi ve gönüllü öğrencilerin bu projeler kapsamındaki etkinliklerde rol almalarının sağlanması ülkemizin toplumsal gelişimine ve yardımlaşmasına katkı sağlayacaktır.

\section{Kaynaklar}

Chen J., Zhou, Y., Zipf, A., Fan, H. (2019). Deep Learning From Multiple Crowds: A Case Study of Humanitarian Mapping. IEEE Transactions on Geoscience and Remote Sensing, 57(3): 1713-1722.

Ellis, H.J.C., Morelli, R. A., Lanerolle, T.R., Hislop, G.W. (2007) Holistic Software Engineering Education Based on a Humanitarian Open Source Project. 20th Conference on Software Engineering Education \& Training (CSEET'07), 3-5 July, Dublin, Ireland.

Ellis, H., Morelli, R.A., Hislop, G.W. (2008). Support for Educating Software Engineers Through Humanitarian, Open Source Projects. 21st IEEE-CS Conference on Software Engineering Education and Training Workshop. 14-17 April, Charleston, USA.

Herrera, A., Prowse, T. (2015). IEEE's Humanitarian Open Source. IEEE 9th International Conference on Standardization and Innovation in Information Technology (SIIT), 7-9 Oct. Sunnyvale, CA, USA.

Hislop, G. W., Ellis, H. J. C. (2017). Humanitarian Open Source Software in Computing Education" Computer IEEE, 50(10):98-101.

Hislop, G.W., Ellis, H.J.C., Morelli, R. (2009). Evaluating Student Experiences in Developing Software for Humanity, Proceedings of the 14th annual ACM SIGCSE conference on Innovation and technology in computer science education, 263-267.

Hsu, H.J. (2012). The Emergence of Free and Open-source Software on Campuses in Taiwan, IEEE Global Humanitarian Technology Conference, 21-24 Oct. Seattle, WA, USA.

Kevin Buffardi, K. (2016). Exploring Realism and Motivation Localized Open Source Software Projects", The 11th International Conference on Computer Science \& Education (ICCSE 2016), August 23-25Nagoya University, Japan. 
Kimei, E., Khamisi, K. (2017). Digitization of antenatal health card and integration with OpenMRS platform: System analysis and design. IST-Africa Week Conference (IST-Africa), 30 May-2 June 2017, Windhoek, Namibia.

Kussmaul, C. (2016). Experience Report: Guiding Faculty \& Students to Participate in Humanitarian FOSS Communities", 2016 IEEE Eighth International Conference on Technology for Education (T4E), 2-4 Dec. Mumbai, India.

Nogay, H. S., Akinci, T.C. (2011). A proposal for visually handicapped students to use electrical control laboratory. Journal of Vibroengineering, 13:245-252.

Nogay, H. S., Akınc1, T. Ç., Erdemir, G. (2018). A Convolutional Neural Network Application For The Classification Of Lung Cancer Types. Academic Journal Industrial Technologies, $5: 7-12$.

Nogay, H. S. (2018). Classification Of Different Cancer Types By Deep Convolutional Neural Networks. Balcan Journal of Electrical\&Computer Engineering, 5: 56-59.

Nogay, H. S., Akıncı, T. Ç., Erdemir, G. (2018). Estimation Of Head $\&$ Neck Cancer Stage By Using Deep Convolutional Neural Networks. Academic Journal Industrial Technologies, 5: 1319.

Nogay, H. S., Akıncı, T. C. (2018). A Convolutional Neural Network Application For Predicting The Locating Of Squamous Cell Carcinoma In The Lung. Balkan Journal of Electrical \& Computer Engineering, 6: 207-210.

Nogay, H. S. (2017). Deep Convolutional Neural Networks To Detect Lung Cancer Stage", The Journal of Cognitive Systems, 2: 33-36.

Nogay, H. S. (2020). Prediction of Post-Treatment Survival Expectancy in Head \& Neck Cancers by Machine Learning Methods", The Journal of Cognitive Systems, 5(1): 23-32.

Nogay, H. S., Adeli, H. (2020). Machine learning (ML) for the diagnosis of autism spectrum disorder (ASD) using brain imaging, Reviews In The Neurosciences, DOI: 10.1515/revneuro-2020-0043, 1-17.

O'Keeffe, E., Moore, A., Mangina E. (2018). Drone-based Reestablishment of Communications for Humanitarian Rescue Organisations. IEEE Radio and Antenna Days of the Indian Ocean (RADIO), 15-18 Oct. Grand Port, Mauritius.

Parra, E., Haiduc, S., James, R. (2016). Making a Difference: An Overview of Humanitarian Free Open Source Systems . IEEE/ACM 38th International Conference on Software Engineering Companion (ICSE-C) , 14-22 May, Austin, TX, USA.

Peter D. P., Shields, M., Sloughter, J.M., Stewart, AJ., Lacrampe, C., Magness, E., Ochavillo, J., Limfueco, J., Mendoza A. (2018). Improving Shoestring Surveys for Off-grid Humanitarian Power Projects: Kilowatts for Humanity and KoboCollect. IEEE Global Humanitarian Technology Conference (GHTC), 18-21 Oct. San Jose, CA, USA.

Shen, H. (2015). Discussion and Analysis of the Crowdsourcing Mode of Public Participation in Emergency Management", 8th International Symposium on Computational Intelligence and Design (ISCID), 12-13 Dec. Hangzhou, China.

Tucker, A., Morelli, R. (2011). The Humanitarian FOSS Project, Goals, Activities, and Outcomes", IEEE Global Humanitarian Technology Conference, 30 Oct.-1 Nov. Seattle, WA, USA.

Walters, C., Caamaño, G.P., German, D.M. (2013). The future of continuous integration in GNOME", 1st International Workshop on Release Engineering (RELENG), 20-20 May, San Francisco, CA, USA. 